\title{
Gender, Identity, and Language: A Case Study in Taiwan's Municipality Mayoral Election in 2010
}

\author{
Ya-Chen Kang
}

\begin{abstract}
Several advocates of Sociolinguistics insights in language use have suggested that a speaker's language use implies his/her status and intended self-image in a certain social structure. To take a close look, in the present study, we assess 11 Taiwan municipality mayoral candidates' (1) slogans, (2) campaign songs, and (3) declaration of contesting the mayoral election. The results reveal that male language users produce more verbs to show their assertive and confidential attitude and ambition, while female users focus more on intimacy and utter softer lexical expression to have a good rapport. What is more, living up to regional expectations, candidates choose more Mandarin in Northern Taiwan but non-Mandarin in Southern Taiwan. In short, to sustain the identity, language users make language choices according to their intended community.
\end{abstract}

Index Terms-Sociolinguistics, gender, identity, politics.

\section{INTRODUCTION}

In sociolinguists' view, language reveals certain messages about culture, social identity, and some other factors related to linguistic variants, for instance, social class, educational level, ethnical groups and gender. The linguistic choices we made demonstrate how we react to the power or social factors [1]. The construction of language use provides us a window to observe the structure of power and social hierarchy prevailing in a certain society. It seems eligible to talk about the power and social structure from the language use in politics, for languages are often controlled and consciously designed to block others' thought [2].

The objective of this study is to investigate what and how people's language preference was utilized and manipulated to appeal their target supporters and to evoke or increase interpersonal relationships and win support in Taiwan municipality mayoral election in 2010. Hence, on the basis of the analysis of their (1) slogans, (2) campaign songs, and (3) declaration of contesting the mayoral election, this study is designed to examine the following two research questions:

1) What are the linguistic features distinguishing female candidates from male candidates?

2) Would there be any linguistic features symbolizing the regions of the campaign?

Manuscript received March 5, 2015; revised June 24, 2015.

Ya-Chen Kang, is with the National Cheng Kung University, Taiwan (e-mail: juliakyc@hotmail.com).

\section{LITERATURE REVIEW}

A number of previous studies on how language interacts with the society within this island are summarized in this section. Ethnic background causing the language conflict is first introduced. Second, tenets of the relation between gender and language use is presented to sustain the stand of exploring the first research question. At last, how the codes react to a given society is reviewed.

\section{A. Ethnic Background and Language Uses in Taiwan}

Taiwan's population seems very diverse. According to the statistic released by Unrepresented Nations and Peoples Organization [3], aborigine, who is composed of 14 tribes, comprises about $2 \%$ and Hakka comprises approximately $14 \%$ of the population. In 1949, mainlanders fled with Chiang Kaishek from mainland China and comprise around $14 \%$ of Taiwan's population. The remainder of the almost $70 \%$ population is Hoklo [3] or so-called Minnanrens [4], which comprises a very high proportion of Taiwanese population. Both Hoklo and Hakka people settled down in this island about one or two centuries earlier than mainlanders and consequently are termed as "Native Taiwanese" in general [3]. As what Discovery Channel [5] in its insight guide about Taiwan states that the largest group, which parallels to the "Native Taiwanese" group, "has deeper connection with the island than mainlanders do." That is, Native Taiwanese group highly regards this island Taiwan as its homeland, not China. They are more likely perceived themselves as Taiwanese, rather than Chinese. Although the percentage numbers in different sources [6], [7] show a slight difference, the native Taiwanese population including Hoklo and Hakka occupies the majority about $85 \%$.

Different ethnics brought in different languages. Mainlanders speak mandarin (termed as Guoyu in Taiwan), while two main Hakka varieties, that is Si-yen and Hoi-liuk, are spoken in Taiwan. The indigenous people are composed of "Sekhoan" (barbarians or mountain tribes) and "Pennpou" (plain tribe). Last, the majority Hoklo people who speak Southern Min primarily came from Choan-chiu (35.2\%) and Chiang-chiu (3.1\%). The Southern Min in Taiwan however was merged with Choan- and Chiang-chiu ones and influences by Japanese language. It eventually turned to be a new form and now is widely recognized as "Taigi" or Taiwanese [8].

The language conflict mainly occurs between native Taiwanese and Mainlanders. Non-Mandarin gained its stand by almost $86 \%$ of the population, whereas "Guoyu" (Mandarin) enhanced its prestige through the National Language Movement (NLM) practiced from mid-1940s to mid-1980 [9]. The policies of the NLM and criticize that the language policies bears "a negative attitude towards the 
non-Mainlander groups" [4]. During that period, non-Mandarin languages were prohibited as the medium for communication in educational institutions, governmental organizations, and media.

The lift of martial law in 1987 is believed as a significant turning point and encouraged people to acknowledge Taiwan as a multi-cultural and multi-lingual country [4]. With the new legalized opposition party's intention, "Taigi" (Taiwanese) has been populated since late 1980s [10], [11]. After the political suppression, non-Mandarin languages nowadays can be heard in public occasions and freely used in mess media. What is more, the Taiwanese identity can be discussed openly. In this light, some people deliberately use their mother tongues to polish the image of Taiwanese identity.

Bearing the phenomenon of Taiwan's heterogeneous population in mind, it is subject to sensitive political issues. The problem derives from the fact that there exist at least four ethnic groups within this island and their languages are not mutually intelligible [8]. The language then used by people often causes a political question within Taiwan [12]. People used to use Mandarin to show their prestigious social status, but some people now tend to use dialects to prove their Taiwanese identity.

\section{B. Gender and Identity}

Another heated topic in sociolinguistics concerns about how men and women manipulate linguistic codes to cohere their social role, namely, how men and women perceive their identity in a certain society. This paper hereby uses the term "gender", rather than "sex", for sex is biologically determined, while gender relates to a social structure [13]. It is widely believed that the ways men and women use the language are distinctive, owing to the cultural ideology which governs how men and women ought to speak [14]. In other words, gender is learned [15]. The gender differences in language are fostered early and origins in their childhood because boys and girls grow in different worlds, even in the same family, region, or culture [16]. What is more, language use by men and women is expected to fill different roles [13]. Childhood separation makes the conversation between men and women as tricky as cross-cultural interaction [17].

Some significant features distinguish women's language use from men's. For instance, the mbmm produced by women means 'I'm listening,' while the mbmm by men should be interpreted as 'I'm agreeing' [13]. Women focus on intimacy and gossip thus is regarded as glue to connect each other, while men focus on independence and prefer the details of politics, news, and sports. What is more, women seem more likely to praise others than men do [16]. To maintain a higher social status, women tend to move toward the prestige norm and thus choose to use official language, while men initiate changes away from the norm and consciously or unconsciously choose the local language [18], [19].

Lakoff [20] summarized nine characteristics for 'women's language', namely, (1) words related to woman's work, (2) empty adjectives, (3) question intonation, (4) the use of hedges, (5) the use of the word 'so', (6) speaking with hypercorrect grammar and (7) super polite forms, (8) a lack of sense of humor, and (9) speaking in italics. Take the forth as an example, the author asserted that women use hedges, for instance "kinda" and "you know", more than men do for ensuring that they are ladylike and nice. Those words convey women's uncertainty and avoidance of unfriendliness. Further, since it seems that men have more power than women, women tend to utilize voice pattern or gestures to catch addressees' attention and convey the semantic force.

\section{Identity in Region}

Language use is not simply different between countries but even within a single community [1]. The different language use in researchers' point of view could be termed as dialects [21]. He maintains that languages can be clustered into two domains, namely, regional and social dialects. Dialects are the result of a certain language varied with two significant factors, that is, time and distance. Regional dialects mark off the people in one region from those in other regions. Regional dialects turn into new languages when those dialects of users are not unintelligible to one another, for instance, Latin becoming French, Spanish, and Italian. Dialect boundary can be geographical or political factor. Social variant, in this light, distinguishes one specific social class or group from the other one by language use, for example, age, gender, or other social characteristics and factors. As what Wardhaugh [21] concludes that when the discussion scope is shifted to social class and ethnicity, it would become more complicated. A person's identity in a community structure will influence people's language choice [4]. In this sense, people belong to different age groups speak differently. Take the language use in Taiwan as an example, certain groups show higher preference to females, younger population, speakers with higher educational level, and residents born or raised in Taipei City [4].

Those reviewed studies shed light on how the choice of language use demonstrates the language users perceive their identity in a certain power structure. In this sense, it seems reasonable for this current paper to gather and analyze linguistic data from election campaign to uncover the identity scenario in Taiwan.

\section{METHOD}

To conduct this study, materials for further analysis will be collected from 11 candidates for the election of the five municipality mayors held on November 27th 2010. The (1) slogans, (2) campaign songs, and (3) declaration of contesting the mayoral election were retrieved from their official websites and the website YouTube.com.

\section{A. Candidates}

11 candidates contested municipality mayoral election held at the end of 2010. Among those candidates, 5 candidates represented Kuomintang (KMT), 5 candidates stood for Democratic Progressive Party (DPP), and 1 non-partisan candidate. 2 candidates contested in each municipality whereas 3 candidates fought in Kaohsiung. Regarding gender, 2 female candidates were nominated by DPP and 1 female candidate by KMT. Among the 11 candidates, 4 were in their incumbencies in their target cities. The detailed information mentioned above is in Table I. 
TABLE I: CANDIDATES FOR THE ELECTION OF MUNICIPALITY MAYORS

\begin{tabular}{|c|c|c|}
\hline & KMT & DPP \\
\hline Taipei City & $\begin{array}{l}\text { Hao, Lung-pin, } M \\
\text { (NKM1) }\end{array}$ & $\begin{array}{l}\text { Su, Chen-chang, } M \\
\text { (NDM2) }\end{array}$ \\
\hline $\begin{array}{l}\text { New Taipei } \\
\text { City }\end{array}$ & Chu, Li-lun, $M$ (NKM3) & $\begin{array}{l}\text { Tsai, Ying-wen, } F \\
\text { (NDF4) }\end{array}$ \\
\hline Taichung City & $\begin{array}{l}\text { Hu, Tzu-chiang, } M \\
\text { (CKM5) }\end{array}$ & $\begin{array}{l}\text { Su, Chia-chuan, } M \\
\text { (CDM6) }\end{array}$ \\
\hline Tainan City & $\begin{array}{l}\text { Kuo, Tien-tsai, } M \\
\text { (SKM7) }\end{array}$ & $\begin{array}{l}\text { Lai, Ching-te, } M \\
\text { (SDM8) }\end{array}$ \\
\hline Kaohsiung & $\begin{array}{l}\text { Huang, Chao-shun, } F \\
\text { (SKF9) }\end{array}$ & Chen, Chu, $F$ (SDF10) \\
\hline
\end{tabular}

Yang, Chiu-hsing, $M$ (SNM11)

Note: "N" = Northern Taiwan, " $C$ " = Central Taiwan, and " $S$ " = Southern Taiwan

Note: " $K$ " = KMT, " $D$ " = DPP, and " $N$ " = Non-partisan candidate

Note: " $M$ " = male and " $F$ " = female

\section{B. Data for Analysis}

This paper analyze those candidates' (1) slogans, (2) campaign songs, and (3) declaration of contesting the mayoral election to explore how they utilize the language to draw support and promote solidarity with their electorates. Among these three resources, for most audio clips of the declaration of election campaign were edited by the mass media; hence, only 2 DPP candidates' audio podcasts are taken into account here.

In Taipei city, the candidate NKM1, who was also the original mayor, used a verb phrase "Taipei takes off" and expects to lead Taipei to fly high, while the candidate NDM2 attempted to convince the residences of Taipei that he can do better than the current one and thus came up with "Taipei surpasses Taipei". This use between now and future is in accordance with the finding of [22]. Comparative use serves as an influential device to persuade others. In New Taipei City, no candidates contesting in this campaign was the current mayor in that target city. The candidate NKM3 claimed that he could turn the city better, while the candidate NDF4 intended to create an image of happiness.

In Taichung, the candidate CKM5 fought within his incumbency and intended to guarantee his citizens a world-class city, whereas his competitor, the candidate CDM6 simply emphasized that he would make every effort to satisfy his residents' wishes.

Both of the two competitors fighting in the election of the Tainan mayors were not in their incumbencies. The candidate SKM7 was born in a small village in Tainan county and famous for its pineapples; therefore, he used the wang-lai, the homophone for pineapple in Taiwanese, to wish for good luck coming to Tainan. The candidate SDM8 claimed that he knew what Tainan's prospects were.

Three candidates contested in Kaohsiung City. With the metaphor embedded in carnations, the candidate SKF9 intended to project the image of a mother's love by adopting the slogan "iron carnation". Metaphor serves as a powerful device to persuade or influence others [22]. The incumbent Kaohsiung mayor SDF10 intended to ensure her citizens a lovely life, while the candidate SNF11 stated that he would upgrade Kaohsiung city with his innovation.

Without the limitation of dialect literacy, the selection of languages in campaign songs appears diverse. NKM1 adopted the song "I believe" in Mandarin, whereas the famous Taiwanese nursery rhyme "Asphalt" was adapted by NDM2 with both Mandarin and Taiwanese. In New Taipei City, NKM3's song "A Young City" is in Mandarin, while NDF4 used the song "With your Company" in the Taiwanese. In Taichung City, the Mandarin song without a title was KMT candidate CKM5's campaign song; DPP candidate CDM6, on the other hand, sang the song "Be your Support" in Taiwanese.

In southern part of Taiwan, the Taiwanese songs "Good Luck to Big Tainan" and "Tainan Battle Song" were belong to the candidate SKM7 and the candidate SDM8 respectively. In Kaohsiung, the popular Taiwanese song "Brave Woman" was adopt by KMT candidate SKF9. SDF10 nominated by DPP sang the song "Iron Flower" in Taiwanese. The independent candidate SNM11 used the Mandarin song "Surmount the Blue and Green" to declare that he could meet his supporters' need without any burdens of either KMT or DPP. All data are shown in Table III in section 4.2 .

\section{RESULTS}

Those 11 candidates' (1) slogans, (2) campaign songs, and (3) declaration of contesting the mayoral election are recorded and analyzed in this following section. The data analysis was set to answer and discuss the research questions addressed in Section I, that is, (1) what linguistic differences distinguish genders and (2) what linguistic characters serve as the results of different regions.

\section{A. Slogans}

Campaign slogans are commonly used to make electors impressive. It is worthy to note that most of Taiwanese people are not familiar with non-Mandarin written expression and thus all slogans were presented in Mandarin. All the data mentioned in Section III-B is schematized here in Table II.

TABLE II: THE LIST OF SLOGANS

\begin{tabular}{ll}
\hline & \multicolumn{1}{c}{ Taipei City } \\
\hline NKM1 & Taipei takes off \\
NDM2 & Taipei surpasses Taipei \\
\hline \multicolumn{2}{c}{ New Taipei City } \\
\hline NKM3 & Turn New Taipei \\
NDF4 & New happiness; New era \\
\hline \multicolumn{2}{c}{ Taichung City } \\
\hline CKM5 & Universally big Taichung \\
CDM6 & Su Chia-chuan can work \\
\hline & Tainan City \\
\hline SKM7 & Comes good luck, big Tainan \\
SDM8 & See the future \\
\hline & Kaohsiung City \\
\hline SKF9 & Iron Carnation \\
SDF10 & The most lovely life in Kaohsiung \\
SNM11 & Upgrade innovation \\
\hline \hline
\end{tabular}

Some interesting features are found here. Among those 11 candidates, six males use verb phrases as their slogans and two men use the adjective "big" to symbolize their ambition. On the other hand, the remaindering three female candidates choose to project the images of love, happiness, and carnation in the upcoming future. 


\section{B. Campaign Songs}

Table III lists the campaign songs reported in Section III-B. From this table, some features are clearly shown. First, the identity of the parties plays a crucial role in language choices here. All DPP candidates in northern, central, and southern Taiwan choose lyrics in Taigi (Taiwanese) as their theme songs. Both KMT candidates in Taipei and New Taipei cities choose theme songs in Mandarin, while KMT candidates in southern Taiwan choose songs in Taiwanese. The title of the non-partisan candidate' theme song suggests the electors not taking political parties into their consideration and is sung in Mandarin.

What is more, some features bear similarity to the language use in slogan. Male candidates use more verbs than females. Even with a noun phrase, male candidates foster a more powerful image by using words, say, "battle" and "big", while the title of two female Kaohsiung candidates' theme songs points out the image of flower and brave women.

The song of the candidate NDF4 expresses the hope of being companied and supported by residents. Interestingly, NDF4's position is totally opposite to CDM6's, for the title of CDM6's theme song says that he will take an active role to stand up for the people in Taichung. We can sense that women tend to take a soft image while men prefer to take active roles.

TABLE III: THE LIST OF CAMPAIGN SONGS

\begin{tabular}{|c|c|c|}
\hline \multicolumn{3}{|c|}{ Taipei City } \\
\hline NKM1 & Mandarin & I Believe \\
\hline NDM2 & Taiwanese \& Mandarin & Asphalt \\
\hline \multicolumn{3}{|c|}{$\begin{array}{c}\text { New Taipei City } \\
\end{array}$} \\
\hline NKM3 & Mandarin & A Young City \\
\hline NDF4 & Taiwanese & With your Company \\
\hline \multicolumn{3}{|c|}{ Taichung City } \\
\hline CKM5 & Mandarin & Big Taichung Marches \\
\hline CDM6 & Taiwanese & Be your Support \\
\hline \multicolumn{3}{|c|}{ Tainan City } \\
\hline SKM7 & Taiwanese & Good Luck to Big Tainan \\
\hline SDM8 & Taiwanese & Tainan Battle Song \\
\hline \multicolumn{3}{|c|}{ Kaohsiung City } \\
\hline SKF9 & Taiwanese & Brave Woman \\
\hline SDF10 & Taiwanese & Iron Flower \\
\hline SNM11 & Mandarin & Surmount the Blue and Green \\
\hline
\end{tabular}

\section{Declaration of Contesting the Mayoral Election}

The words candidates utter to declare their ambition to attend campaign may demonstrate how men and women are sensitive to their social roles. The available accesses to whole complete speech archives are DPP candidate NDF4's and DPP candidate NDM2's declaration. The others' collected from the Internet were edited by the mass media. To prevent any misunderstanding misled by those fragmented and incomplete episodes, this current study takes these two complete videos into account.

Both retrieved clips are DPP candidates' speeches. Although the popularity of Taiwanese or "Taigi" is contributed by DPP [10], [11], they did not deliver their speeches in Taiwanese. NDF4 declared her decision to fight municipality mayoral election at the port at which Dr. Mackay landed and started his valuable contribution. She mentioned the public's expectation was the power to urge her contest the election. She encouraged herself that she would put all her effort and work with New Taipei City citizens to make the city better. NDM2, on the other hand, chose to declare his willing at a famous temple in Taipei City. He emphasized his sense of responsibility would monitor his performance in his incumbencies. In short, DPP is commonly believed to cling to the ideology of being native Taiwanese and promoting local Taiwanese culture. However, in both clips, they utter in Mandarin instead.

\section{DISCUSSION}

The different choices in language are believed to reflect social status or social structure [23]. The first research question stated in Section $\mathrm{I}$ is whether there would be any differences distinguishing female candidates from male candidates. On the other hand, the second research question is whether any linguistic features symbolize regions. This section delves into this issue.

\section{A. Linguistic Features of Genders}

Along the lines of the previous study, man's language style is to give the command and gain control [17] but women tend to portray a softer image to promote interactions and encourage addressees' participation and company. Take slogans as an example, men seem more likely to use verb phrase, whereas women prefer a noun phrase with the image of love.

In a patriarchy society, men make public speaking with assertive, dominant, confident style [15], whereas women's avoidance of strong words expresses women's uncertainty and lack of confidence [23]. As for their campaign songs, men showed their high ambition and aggressiveness by lyrics, while women intended to strengthen an image of traditional feminine role, for instance, flowers, love, or happiness. What is more, to bear Tannen's [16] finding in mind, women focus on intimacy. As a result, the female candidate expresses the hope of being surrounded by the residents. The male candidate, on the other hand, states that he will stand up for the electors.

The use of "I" claims responsibility for the future much stronger than the use "we" [22]. At the declaration of contesting the mayoral election, the female candidate uses "we" to refer to herself whereas the male candidate uses "I" directly to refer to himself instead.

\section{B. Linguistic Features in Regions}

The second research question is regarding how candidates make linguistic choices to show their identity in regions. First, the results show that almost all candidates, even for KMT candidates, in southern Taiwan tended to feature theme songs in Taiwanese, rather than Mandarin. It shows that the regional ideology can outplay the ideology of a party.

In northern part of Taiwan, where is commonly believed that more mainlanders are located in and people there use Mandarin more [24], DPP candidates in Taipei City and New Taipei City made a speech in Mandarin to appeal to their electors, even though they sang campaign songs in Taiwanese to sustain the identity. DPP candidates in Taipei City NDM2 even adopt campaign song in both Taiwanese and Mandarin. As we can see, even if candidates attempt to sustain their preferential identities, again, it is still overridden by the regional or community ideology. 
DPP is widely believed to cling to the Taiwanese ideology and devote lots of effort to promote local Taiwanese language and culture. However, in both NDF4 and NDM2 clips, they utter in Mandarin instead. They obviously set the regional expectation prior to their party identity.

What is more, although women tend to use prestige language more, which refers to Mandarin in Taiwan [4], [18], in order to earn more supports, all female candidates' themes songs, nominated either KMT or DPP, are in Taiwanese in southern part of Taiwan.

In short, from the examples of the DPP candidates in northern Taiwan, KMT candidates, in south, and female candidates in south, although they use their preferential language to sharpen their identity, they still need to take regional ideology into their consideration and use the regionally local language in some other occasions to reduce the ethnical conflict and earn more supports.

\section{CONCLUSION}

As what is discussed, the linguistic choices made by people show how language users react to the power or social relationship [1] and accord with their identities which are shaped by social expectation. The results derived from this study reveal that the choices of language varieties are determined by language user's gender and his/her region.

The results shed light on how the different language uses reflect different language identities. First, for instance, men used more verbs than women did. Women's word choices demonstrate their uncertainty and their desire to foster intimacy or have a good rapper with others. Second, although DPP candidates generally prefer to use native Taiwanese to show their identity, they however would use Mandarin in some occasions when they are located in northern Taiwan. The phenomenon that female candidates in southern part of Taiwan use Taiwanese, rather than prestige Mandarin proves that the expected identity would outplay their initiatives.

However, some inevitable obstacles exit here. First, female samples here are merely three and considerably limited. It seems exciting to gather more data into analysis. Second, the data sources are constrained within the Internet. The data on what and how the language those candidates used to interact with their voters can provide a more detailed and careful materials. It would be the other interesting topic to look at. For further research, a survey of the public's viewpoint of the language in campaign is suggested to examine whether those politicians successfully create a given image for the public. Also, it can also serve as a window that how the public perceive those language preferences.

\section{REFERENCES}

[1] S. Wareing, "What is language and what does it do?" in Language, Society and Power: An Introduction, F. Nuessel, Ed. London: Routledge, 2004, pp. 1-16.

[2] N. Chomsky, Language and Politics, UK: AK Press, 2004, pp. 105-118.

[3] UNPO. (December 2009). Taiwan. [Online]. Available: http://unpo.org/members/7908

[4] H. N. Yeh et al. (April 2004). Language use in Taiwan: Language proficiency and domain analysis. Journal of Taiwan Normal University: Humanities \& Social Sciences. [Online]. 49(1). pp. 75108. Available: http://www.ntnu.edu.tw/acad/epub/j49/j491-14.htm

[5] V. Kim, Insight Guides: Taiwan, London: Discovery Channel, APA Publications, 2008, pp. 51-54.

[6] S. F. Huang, Language, Society, and Ethnic Identity, Taipei: Crane, 1993, ch. 2, pp. 19-48.

[7] W. C. Lin, "Language competition and challenges in pluralingual education: The case of a Hakka school in Taiwan," L1-Educational Studies in Language and Literature, vol. 12, pp. 1-19, October 2012.

[8] W. V. T. Chiung, "Language and ethnic identity in Taiwan," presented at the $7^{\text {th }}$ North American Taiwan Studies Conference, University of Washington, Seattle, June 2001.

[9] F. F. Tsao, "The language planning situation in Taiwan," Journal of Multilingual and Multicultural Development, vol. 20 no. 4-5, pp. 328-375, September 1999.

[10] Hsiau, "Language ideology in Taiwan: The KMT's language policy, the Taiyu language movement, and ethnic politics," Journal of Multilingual and Multicultural Development, vol. 18 no. 4, pp. 302-315, July 1997.

[11] T. L. Sandel, W. Y. Chao, and C. H. Liang, "Language shift and language accommodation across family generations in Taiwan," Journal of Multilingual and Multicultural Development, vol. 27, no. 2, pp. 126-147, March 2006.

[12] Lee, "Language attitudes and identity in Taiwan," M.S. thesis, Dept. Psychology. Univ. of Pittsburgh, Pittsburgh, USA, 2003.

[13] R. Wardhaugh, An Introduction to Sociolinguistics, $6^{\text {th }}$ ed. UK: Blackwell Publishing, 2010, ch. 13, pp. 333-355.

[14] M. Bucholtz, "Editor's introduction," in Language and Woman's Place, M. Bucholtz, Ed. New York: Oxford University, 2004, pp. 3-14.

[15] J. T. Wood, Gendered Lives: Communication, Gender, and Culture, $6^{\text {th }}$ ed. Canada: Wadsworth, 2005, ch. 1, pp. 14-35.

[16] Tannen, You Just Don't Understand: Women and Men in Conversation, NY: Harper Collins Publishers, 2007, pp. 13-24.

[17] Cameron, The Myth of Mars and Venus, New York: Oxford University, 2007, ch. 4, pp. 59-79.

[18] J. Coates, Women, Men, and Language, $3^{\text {rd }}$ ed. UK: Person Education Limited, 2004, ch. 10, pp. 171-188.

[19] S. Romaine, "Variation in language and gender," in The Handbook of Language and Gender, J. Holmesand and M. Meyerhoff, Eds. UK: Blackwell Publishing, 2003, pp. 98-118.

[20] R. T. Lakoff, "Why women are ladies," in Language and Woman's Place, M. Bucholtz, Ed. New York: Oxford University, 2004, pp. 77-102.

[21] R. Wardhaugh, An Introduction to Sociolinguistics, $6^{\text {th }}$ ed. UK: Blackwell Publishing, 2010, ch. 6, pp. 137-165.

[22] J. Jones and J. S. Peccei, "Language and politics," in Language, Society and Power: An Introduction, F. Nuessel, Ed. London: Routledge, 2004, pp. 35-53.

[23] J. Holmes, An Introduction to Sociolinguistics, $3^{\text {rd }}$ ed. London: Person Education, 2008, ch. 1, pp. 1-16.

[24] S. F. Huang, Language, Society, and Ethnic Identity, Taipei: Crane. 1993, ch. 5, pp. 128-173.

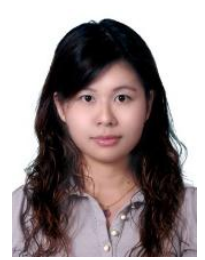

Ya-Chen Kang was born in Tainan, Taiwan on January 9, 1982. Kang got an MA degree in TEFL at Tam Kang University (TKU) in Taipei City, Taiwan in 2009. She then pursuing a $\mathrm{PhD}$ degree in linguistics at the Dept. of Foreign Languages and Literature at National Cheng Kung Univ. (NCKU) in Tainan City, Taiwan since 2012.

She teaches linguistics and TEFL as a part-time lecturer at four universities in southern Taiwan: National Univ. of Tainan (NUTN), Southern Taiwan Univ. of Science and Technology (STUST), and Tainan Univ. of Technology (TUT) in Tainan, and Wenzao Ursuline Univ. of Languages in Kaohsiung. Before coming back to Tainan, she was a part-time lecturer at Tam Kang Univ. (TKU) and a teaching supervisor at an Adult Language Institution in Taipei.

In 2008, she and her MA supervisor, Y. H. Hu, presented a paper "Bring or Take: That's the Question in Teaching Deictic Shifts in FL Classrooms," at Second Language Research Forum 11th at University of Hawaii. Later, in 2009, they presented "Bring and take vs. Na 拿 and Dai 帶: A comparative study of English and Chinese motion verbs and its pedagogical implications," at British Association for Applied Linguistics (BAAL) 42nd Annual Meeting at Newcastle University in UK. She is interested in cognitive linguistics and sociolinguistics. Currently, she is conducting research for her thesis on metaphorical use in Chinese idioms. 